Original Article

\title{
Effects of an upper-limb exercise program for improving muscular strength and range of movement on respiratory function of stroke patients
}

\author{
Dong-Hyun Kim, $\mathrm{PhD}^{1)}$, SAnG-Hun JANG, $\mathrm{PhD}^{2)^{*}}$ \\ 1) Department of Occupational Therapy, Gimcheon University, Republic of Korea \\ 2) Department of Physical Therapy, Gimcheon University: 214 Daehak-ro, Gimcheon-si, \\ Gyeongsangbuk-do 39528, Republic of Korea
}

\begin{abstract}
Purpose] This study aims to investigate the effects of upper-limb exercises on the respiratory functions of stroke patients. [Subjects and Methods] This study was performed with 25 stroke patients. The subjects were divided into the control group $(\mathrm{n}=12)$ which did not perform upper arm training and the experimental group $(n=13)$ which conducted upper arm training. Forced vital capacity and forced expiratory volume in the first second, both of which are used in this study, are well-known indicators of respiratory capabilities. Peak cough flow is used to indicate cough capability. [Results] Concerning changes in forced vital capacity, forced expiratory volume in the first second and the peak cough flow of each group after the exercise, while the control group did not show significant differences, the experimental group showed statistically significant increases. [Conclusion] The results of the study indicate that exercise programs that increase the mobility of upper limbs and increase muscular strength have the effect of normalizing vertebral alignment for stroke patients, and thus can provide effective interventions for improving respiratory function.

Key words: Upper limb exercise, Stroke, Respiratory function
\end{abstract}

(This article was submitted Apr. 7, 2016, and was accepted Jun. 16, 2016)

\section{INTRODUCTION}

Stroke causes sensory deficits, changes in muscular tension, and lack of physical activity ${ }^{1)}$. These damaging effects lead to biomechanical changes in respiration ${ }^{2}$, which are due to the weakening of the respiratory muscles of the affected side, inappropriate diaphragmatic action, and the movement of the intercostal muscles ${ }^{3)}$. All of these factors can reduce the total lung capacity and vital capacity of stroke patients ${ }^{4}$.

Training of respiratory muscles, such as inspiratory muscles, has commonly been conducted to improve the respiratory function of stroke patients ${ }^{5}$. However, respiration is closely related to the upper limbs, because in order to breathe, the movement of the trunk is necessary, which in turn is related to the movement of the upper limbs. It has been reported that the coordination of the trunk can prevent compensation movements of the upper limbs in stroke patients, indicating that the movement of the upper limbs is closely linked to the movement of the trunk ${ }^{6}$. It can then be inferred that stroke patients may experience difficulties with trunk movements due to issues in the movement of the upper limb on the affected side, which can undermine respiratory functions.

Therefore, this study aims to investigate the effects of these exercises on the respiratory functions of stroke patients by having them perform upper-limb exercises and measuring their respiratory functions after the exercise.

\footnotetext{
*Corresponding author. Sang-Hun Jang (E-mail: upsh22@hanmail.net)

(C)2016 The Society of Physical Therapy Science. Published by IPEC Inc.

This is an open-access article distributed under the terms of the Creative Commons Attribution Non-Commercial No Derivatives (by-nc-nd) License $<$ http://creativecommons.org/licenses/by-nc-nd/4.0/>.
} 


\section{SUBJECTS AND METHODS}

The subjects of this study were stroke patients hospitalized in the H Rehabilitation Hospital in Daegu, South Korea. Experiments were conducted from August to October, 2015, with patients who understood the motives of the study and agreed to participate. The subjects consisted of 25 patients with no medical history of respiratory diseases, no signs of lung disease observed in radioactive and physical examinations, and no serious cognitive impairments (over 24 points on the MMSE-K), such as aphasia or dementia, which could hinder the experiment. A physiotherapist who was blinded from the assessment entered all the demographic data into a computer program designed for stratified randomization. The stratification performed before randomization was based on gender (male and female) and side of hemiplegia (left and right). By way of random assignment, the subjects were divided into the control group $(\mathrm{CG}, \mathrm{n}=12)$, which did not perform upper arm training and the experimental group (UATG, $n=13$ ), which conducted upper arm training. The study subjects provided written informed consent prior to participation, according to the ethical standards of the Declaration of Helsinki.

The interventions were conducted five days a week for a four week period. The two groups received the same physiotherapy they had already received, consisting of 30 minutes of exercise, 15 minutes of rehabilitation ergometer, and 15 minutes of functional electrical stimulation. The UATG group underwent 30 minutes of upper arm training in addition to the physiotherapy.

For the upper arm training, the program used by Volpe et al. was revised and applied to improve muscular strength and the range of movement of the upper limb on the affected side ${ }^{7)}$. The program consisted of three elements, namely, active assisted arm exercise, static stretching, and a goal-directed planar reaching task. First, the active assisted arm exercise was performed, which included flexion of the glenohumeral joint and strengthening of the muscles near the scapula. During flexion of the glenohumeral joint, the patient was seated comfortably on the side of an adjustable table while the therapist led the exercise to maintain an upright trunk positioning, prevent compensatory trunk movements, and minimize the increase of abnormal muscle tone. The angle of the glenohumeral joint flexion did not exceed 90 degrees so as not to cause pain. With the patient sitting on the edge of a mat, the training included three sessions (10 repetitions per session) for 10 minutes. Between sessions, the patient was given 30 seconds of rest. Exercises for strengthening the muscles near the scapula were conducted for 10 minutes. Scapular elevation was performed in five concentric and five isometric movements, followed by 30 seconds of rest. After that, depression, retraction, and protraction were performed in the same manner in five concentric and five isometric movements. Then, the second program, the static stretching of the adductor, internal rotator, and elbow flexors, was conducted for five minutes. While lying straight, the patient performed 90 degrees of glenohumeral joint abduction with the elbow in full extension. As for glenohumeral joint abduction, lateral rotation was performed to the extent that it did not cause pain. Lastly, the third program, goal directed movements using a skate board system, was conducted for five minutes. The patient placed his/her forearm on a skate board that had almost zero friction with the table while performing 35 degrees of shoulder flexion. Then, the patient makes a motion as if drawing the number eight, and moves left and right, and forward and backward.

The pulmonary function calculator (Micro Medical Ltd., UK) of the Micro Spirometer (Micro Medical Ltd., UK) was used to measure respiratory function. With the patient seated on a treatment table with adjustable height, the forced vital capacity (FVC) and the forced expiratory volume at one second (FEV1) were measured. The FVC is defined as the amount of air that the patient breathes out as quickly as possible after breathing in as much air as possible. The FEV1 is defined as the amount of air that the patient breathes out as quickly as possible for one second after breathing in as much air as possible. As for cough function, the peak cough flow (PCF) was measured using a Peck flow meter (Cardinal Health 232 Ltd., UK). The patient was put in the same position as when lung function was measured. Measurement was taken after the patient had breathed in as much air as possible and coughed out as vigorously as possible.

The paired t-test was conducted to compare changes in the values of respiratory function and cough function according to the period of each group. To test the statistical significance, the level of significance was set at 0.05 . The results of the experiment are presented in terms of average and standard deviation. The findings were statistically analyzed with PASW 18.0 for Windows.

\section{RESULTS}

There were a total of 25 subjects, with 13 in the UATG, and 12 in the CG. The general characteristics of the subjects are shown in Table 1.

The paired t-test was conducted to compare the respiratory functions of each group before and after the exercise. The results are shown in Table 2. As for changes in the FVC of each group after the exercise, no significant differences were observed in the CG, while the UATG showed statistically significant increases, with $1,783.3 \pm 523.3 \mathrm{ml}$ before the exercise and $1,841.7 \pm 481.5 \mathrm{ml}$ after the exercise. Concerning changes in the FEV1 of each group after the exercise, while the CG did not show significant differences, the UATG showed statistically significant increases, with 1,531.8 $\pm 674.9 \mathrm{ml}$ before the exercise and 1,557.3 $\pm 608.6 \mathrm{ml}$ after the exercise.

Changes in the PCF of each group after the exercise are shown in Table 3. The CG did not show significant differences 
Table 1. General characteristics of the subjects (number or mean $\pm \mathrm{SD}$ )

\begin{tabular}{lcc}
\hline Variables & $\begin{array}{c}\text { Control group } \\
(\mathrm{n}=12)\end{array}$ & $\begin{array}{c}\text { Experimental } \\
\text { group }(\mathrm{n}=13)\end{array}$ \\
\hline Gender (male/female) & $4 / 8$ & $4 / 9$ \\
Paretic side (left/right) & $7 / 5$ & $9 / 4$ \\
Age (years) & $70.8 \pm 13.3$ & $65.2 \pm 14.1$ \\
Time since stroke (months) & $27.2 \pm 15.4$ & $24.3 \pm 9.4$ \\
Height $(\mathrm{cm})$ & $164.2 \pm 8.5$ & $162.4 \pm 10.3$ \\
Weight $(\mathrm{kg})$ & $58.2 \pm 12.1$ & $61.7 \pm 9.4$ \\
\hline
\end{tabular}

Table 2. Comparison of pre and post pulmonary function $($ mean $\pm \mathrm{SD})$

\begin{tabular}{llcc}
\hline Group & Variables & Pre & Post \\
\hline UATG & FVC $(\mathrm{ml}) *^{*}$ & $1,783.3 \pm 523.3$ & $1,841.7 \pm 481.5$ \\
& FEV $_{1}(\mathrm{ml})^{*}$ & $1,712.3 \pm 761.2$ & $1,759.2 \pm 743.5$ \\
CG & FVC $(\mathrm{ml})$ & $1,531.8 \pm 674.9$ & $1,557.3 \pm 608.6$ \\
& FEV $_{1}(\mathrm{ml})$ & $1,403.1 \pm 642.5$ & $1,462.3 \pm 678.3$ \\
\hline
\end{tabular}

UATG: upper arm training group, CG: control group, FVC: forced vital capacity, $\mathrm{FEV}_{1}$ : forced expiratory volume at $1 \mathrm{sec}$ ond, ${ }^{*} \mathrm{p}<0.05$

Table 3. Comparison of pre and post coughing function $($ mean $\pm \mathrm{SD})$

\begin{tabular}{llll}
\hline Group & Variables & \multicolumn{1}{c}{ Pre } & \multicolumn{1}{c}{ Post } \\
\hline UATG & PCF $(\mathrm{ml})^{*}$ & $175.0 \pm 75.9$ & $182.9 \pm 77.9$ \\
CG & PCF $(\mathrm{ml})$ & $145.8 \pm 104.1$ & $149.6 \pm 105.0$ \\
\hline
\end{tabular}

UATG: upper arm training group, CG: control group, PCF: peak cough flow, ${ }^{*} \mathrm{p}<0.05$

while the UATG exhibited statistically significant increases with $175.0 \pm 75.9 \mathrm{ml} / \mathrm{min}$ before the exercise, and $182.9 \pm$ $77.9 \mathrm{ml} / \mathrm{min}$ after the exercise.

\section{DISCUSSION}

This study used FVC, FEV1, and PCF as indicators of respiratory function to examine the effect of upper-limb exercises on the respiratory function of stroke patients. The FVC and FEV1 are known as important indicators of damage to the neuro-respiratory system ${ }^{4}$. Moreover, since damage to the cough function increases the risks of aspiration and causes chest infections due to a decreased ability to clear the cilia of mucous, the PCF is a critical method of measuring damage to the cough function after stroke ${ }^{8)}$.

The upper-limb exercises conducted in this study consisted of flexion of the glenohumeral joint and exercises designed to strengthen muscles near the scapula. Vertebral misalignment can cause respiratory function to deteriorate ${ }^{9}$. Previous studies have indicated that exercises that increase the movement of the shoulder joint and enhance muscles near the scapula of stroke patients increase the upward rotations of the scapula, which in turn reduces abnormal lateral spinal deviation ${ }^{10}$. In the current study, the UATG showed increases in FVC, FEV1, and PCF, compared with the CG. This indicates that if a therapist provides upper-limb exercises for stroke patients in a way that does not cause compensatory movement of the trunk, it could have positive effects on the abnormal trunk angle and could improve respiratory function. The results of previous studies also show that the enhancement of the shoulder girdle muscle as well as respiratory muscle exercise can provide effective interventions to normalize the abnormal spinal curvature.

Muscle-strengthening exercises have not been recommended as rehabilitation exercises for the reason that they aggravate the spasticity of stroke patients. However, it has been reported in recent years that muscle-strengthening exercises do not affect spasticity, and there is a growing interest in such exercises as critical treatment methods for improving functional abilities $^{11,12)}$. In addition, it has been reported that muscle-strengthening exercises are favorable training methods for helping stroke patients regain neuromotor function, as they increase motor unit recruitment and reduce the stiffness and reflexive hyperactivation of muscles while maintaining the muscles' functional extensibility ${ }^{13)}$. There are reports maintaining that, for patients suffering from chronic obstructive pulmonary disease, muscle-strengthening exercises have a positive impact not only on the muscle enhancement of limbs, but also on respiratory functions such as FVC and FEV1 ${ }^{14)}$. Based on the results of the abovementioned studies, exercises for strengthening the muscles of limbs are considered to have favorable effects on the respiratory functions of stroke patients.

Upper-limb exercises using skateboards, as in the current study, are often used to increase the range of motion (ROM) of upper limbs and restore the functions of upper limbs ${ }^{15)}$. Regaining the ROM of upper limbs can help in reducing the compensation movement of the trunk and supporting the trunk in an upright position. Upper-limb exercises using skateboards, as in the current study, are considered to have increased the ROM of upper limbs, which in turn helped normalize vertebral misalignment and increase the respiratory function of stroke patients.

Moreover, continued upper-limb exercises of appropriate intensity are reported to increase the density of capillaries and 
improve their ability to carry oxygen ${ }^{16)}$. Thus, it can be anticipated that the four week upper-limb exercise program conducted in the current study can help increase the body's ability to carry oxygen, improve endurance and respiratory functions, and assist in performing the activities of daily living.

This study examined the effects of upper-limb exercise programs on the respiratory function of stroke patients. The results of the study indicate that exercise programs that increase the mobility of upper limbs and increase muscular strength have the effect of normalizing vertebral alignment for stroke patients, and thus can provide effective interventions for improving respiratory function. While exercises for improving the respiratory function of stroke patients have focused on the training of respiratory muscles, the current study explains the effect of upper-limb exercises in improving respiratory function. Hence, there is a need for continued and multi-dimensional research on respiratory function related to the movement of the upper limbs of stroke patients.

\section{ACKNOWLEDGEMENT}

This work was supported by the 2015 Gimcheon University Research Grant.

\section{REFERENCES}

1) Liao CF, Liaw LJ, Wang RY, et al.: Relationship between trunk stability during voluntary limb and trunk movements and clinical measurements of patients with chronic stroke. J Phys Ther Sci, 2015, 27: 2201-2206. [Medline] [CrossRef]

2) Polese JC, Pinheiro MB, Faria CD, et al.: Strength of the respiratory and lower limb muscles and functional capacity in chronic stroke survivors with different physical activity levels. Braz J Phys Ther, 2013, 17: 487-493. [Medline] [CrossRef]

3) Voyvoda N, Yücel C, Karataş G, et al.: An evaluation of diaphragmatic movements in hemiplegic patients. Br J Radiol, 2012, 85: 411-414. [Medline] [CrossRef]

4) Hozawa A, Billings JL, Shahar E, et al.: Lung function and ischemic stroke incidence: the atherosclerosis risk in communities study. Chest, 2006, 130: 1642-1649. [Medline] [CrossRef]

5) Britto RR, Rezende NR, Marinho KC, et al.: Inspiratory muscular training in chronic stroke survivors: a randomized controlled trial. Arch Phys Med Rehabil, 2011, 92: 184-190. [Medline] [CrossRef]

6) Michaelsen SM, Levin MF: Short-term effects of practice with trunk restraint on reaching movements in patients with chronic stroke: a controlled trial. Stroke, 2004, 35: 1914-1919. [Medline] [CrossRef]

7) Volpe BT, Lynch D, Rykman-Berland A, et al.: Intensive sensorimotor arm training mediated by therapist or robot improves hemiparesis in patients with chronic stroke. Neurorehabil Neural Repair, 2008, 22: 305-310. [Medline] [CrossRef]

8) Zhou Z, Vincent F, Salle JY, et al.: Acute stroke phase voluntary cough and correlation with maximum phonation time. Am J Phys Med Rehabil, 2012, 91: 494-500. [Medline] [CrossRef]

9) Obayashi H, Urabe Y, Yamanaka Y, et al.: Effects of respiratory-muscle exercise on spinal curvature. J Sport Rehabil, 2012, 21: 63-68. [Medline]

10) Awad A, Shaker H, Shendy W, et al.: Effect of shoulder girdle strengthening on trunk alignment in patients with stroke. J Phys Ther Sci, 2015, 27: 2195-2200. [Medline] [CrossRef]

11) Ada L, Dorsch S, Canning CG: Strengthening interventions increase strength and improve activity after stroke: a systematic review. Aust J Physiother, 2006, 52: 241-248. [Medline] [CrossRef]

12) Yang YR, Wang RY, Lin KH, et al.: Task-oriented progressive resistance strength training improves muscle strength and functional performance in individuals with stroke. Clin Rehabil, 2006, 20: 860-870. [Medline]

13) Shepherd RB: Exercise and training to optimize functional motor performance in stroke: driving neural reorganization? Neural Plast, 2001, 8: 121-129. [Medline] [CrossRef]

14) Hoff J, Tjønna AE, Steinshamn S, et al.: Maximal strength training of the legs in COPD: a therapy for mechanical inefficiency. Med Sci Sports Exerc, 2007, 39: 220-226. [Medline] [CrossRef]

15) Chanubol R, Wongphaet $P$, Chavanich N, et al.: A randomized controlled trial of Cognitive Sensory Motor Training Therapy on the recovery of arm function in acute stroke patients. Clin Rehabil, 2012, 26: 1096-1104. [Medline] [CrossRef]

16) Boushel R, Ara I, Gnaiger E, et al.: Low-intensity training increases peak arm VO2 by enhancing both convective and diffusive $\mathrm{O} 2$ delivery. Acta Physiol (Oxf), 2014, 211: 122-134. [Medline] [CrossRef] 